\title{
A Imagem e as Ciências Humanas: a poética visual como possibilidade de construção do saber
}

\author{
Luis Artur Costa' \\ Tania Mara Galli da Fonseca' \\ Margarete $\mathrm{Axt}^{1}$ \\ 'Universidade Federal do Rio Grande do Sul (UFRGS), Porto Alegre/RS - Brasil
}

RESUMO - A Imagem e as Ciências Humanas: a poética visual como possibilidade de construção do saber. Este artigo propõe uma nova perspectiva sobre o papel da imagem na produção do conhecimento, especialmente no que se refere às ciências humanas. Na modernidade científica a imagem foi considerada um ente de ontologia falha. Na contemporaneidade a imagem ganhou uma nova importância: ela se tornou nosso principal meio de expressão e comunicação além de servir importante estratégia de pesquisa. Por outro lado, a produção de saber/conhecimento através de imagens poéticas e experimentais é ainda hoje um tabu na academia. Contra esta concepção, muitos artistas e pensadores criaram outro modo de pensar as relações entre imagem e ciência: a imagem é real e imanente ao nosso mundo, posto que ambos nada mais são do que ação. A imagem poética produz uma grande variedade de transformações nos nossos modos de ver ao mundo, resultando em uma interessante estratégia para a pesquisa.

Palavras-chave: Imagem. Epistemologia. Poética. Metodologia. Whitehead.

ABSTRACT - The Image and the Humanities: visual poetics as the possibility of construction of knowledge. The article proposes a new perspective on the role of image in the production of knowledge, particularly with respect to the humanities. In the scientific modernity, image was regarded as an entity of imperfect ontology. Nowadays images have acquired a new importance: they have become our chief means of expression and communication, apart from their important role in research strategies. On the other hand, the production of knowledge through experimental and poetic images is still taboo in academia. Against such notion, many artists and thinkers have created a new way of conceiving the relations between images and science: the image is real and immanent to our world, since both are nothing more than action. The poetic image produces a large variety of transformations in our ways of seeing the world, resulting in an interesting research strategy.

Keywords: Image. Epistemology. Poetics. Methodology. Whitehead.

Educação \& Realidade, Porto Alegre, v. 39, n. 4, p. 1153-1168, out./dez. 2014.1153

Disponível em: <http://www.ufrgs.br/edu_realidade> 
A Imagem e as Ciências Humanas

Muitos são os que desconfiam das imagens por sua beleza imediata e superficialidade. Temem ser enganados por ela, mas, de fato, o que fazem é apenas exigir dessa o que ela não pode ser: buscam a confirmação (verificação, evidência, prova etc.) de coisas para além da imagem na própria imagem, ao modo dos homens que buscam inutilmente o celibato e o jejum para serem mais parecidos com Deus. Podemos criticá-los parafraseando Nietzsche (1999): pobres dos homens que temem ser enganados, mal sabem que a vida é feita de engano e falsidade, pois é pelo artifício que criamos a possibilidade de ser. A imagem, a aparência, o simulacro, costumam se associar à mentira, à idolatria. Peça irônica, pois mesmo a ciência, que tem como padroeiro São Tomé e sua escopofilia (ver para crer) é um tanto escopofóbica (as aparências enganam), principalmente quando fala de sutilezas como gentes e cidades. De fato, tantas foram - e são - as promessas impostas para as imagens pelas ciências que muitos homens se ressentiram das mesmas. No entanto, não foram as imagens que mentiram, mas sim os homens que buscaram nelas algo que não fora imagem.

\section{Ciência e Imagem: uma longa e tortuosa relação}

A visão se apresenta na longa construção das ciências enquanto sentido privilegiado. Sentido próprio da observação, pois permite uma proximidade à distância: ver sem tocar. Ligação luminosa intangível que não interfere sobre o visto, apesar de ser compreendida como visão direta (imediata) do que há: janela para o mundo ou perscrutadora de evidências. Com o olhar poderíamos ver como as coisas são por si sem interferir com nossa presença. Além do mais, aprendemos a transformar nosso olhar, possibilitando a visão de fenômenos jamais vistos a olho nu, desvelando mundos invisíveis que fascinavam e fascinam aos cientistas em geral. Por isso, variar ao nosso olhar criando outras possibilidades de ver foi sempre um dos agenciamentos mais recorrentes entre a ciência e o olhar: lunetas, telescópios, microscópios, raios-X, infravermelho, positrons e daí para a ampla e ilimitada gama de raios emitidos e lidos que geram visibilidades as quais pouco ou nada tem a ver com a sensibilidade da nossa retina.

Mas mais do que variar a perspectiva do olhar, na ciência a visão sempre foi valorizada por sua capacidade de atestar a existência sem tocar ou cortar ao corpo em questão. O buraco da luneta, a circunferência da lupa, o buraco da fechadura, a retangular transparência unidirecional da falsa reflexibilidade dos espelhos nas salas de atendimento psicológico: todos os estratagemas tecnocientíficos do olhar oferecendo ao cientista voyeur a possibilidade de ver sem implicar-se. Uma escopofilia espetaculosa que dá a ver o saber já recortado segundo seu enquadramento simplificador. Mas, apesar de toda proeminência contemporânea da visualidade, nossas ciências não a veem como imagem-visual, só a veem pela formalização do visual em números ou palavras (imagem-formal).

1154 Educação \& Realidade, Porto Alegre, v. 39, n. 4, p. 1153-1168, out./dez. 2014 Disponível em: <http://www.ufrgs.br/edu_realidade> 
Para a ciência há que se ultrapassar a mera aparência de algum modo para a visão alçar o saber: "Imagens são vistas como pertencendo eminentemente ao campo sensível e, para os cientistas sociais, esse campo é um campo onde têm legitimidade apenas os artistas" (Novaes, 2009, p. 43). De fato, na ciência, a imagem é reduzida a duas funções totais: vestígio e representação inteligível do real. Há que se submeter a imagem à relação de analogia com as coisas e à relação de formalização a um só tempo. Margaret Mead e Gregory Bateson, por exemplo, captaram imagens em suas expedições antropológicas com o fim de descrever e classificar os tipos nativos ou para descrever seus comportamentos típicos: formalizar representações categoriais. Do mesmo modo, um dos pioneiros do filme etnográfico, Robert Gardner, exaltava a inscrição audiovisual como a possibilidade de um olhar sem perspectiva, a objetivação representacional máxima: “[...] evidência de um tipo direto e não ambíguo, sendo a realidade capturada instantaneamente e não sofrendo distorções devido a falhas de vista, memória ou interpretação semântica" (Gardner, 1963 apud Burke, 2004, p. 194).

Outro exemplo desta longa relação entre a imagem plástica e a pesquisa é o estudo destas imagens para melhor perspectivar um período histórico ou uma cultura a partir da imagética visual nestes produzida: o estudo de pinturas do século XIII como se fossem janelas para as paisagens do passado, por exemplo. Este é o costume de tomar a imagem como representação (janela) reduzindo a imagem a uma evidência de outra coisa que não ela (costume, veste, evento etc.): representação mimética do que havia em um local ou período, cristalização de uma paisagem e de um instante em uma superfície. Outra opção muitas vezes presente nestes estudos das imagéticas de uma época é a digressão sobre simbolismos secretos escondidos sob figuras míticas e sagradas. Nesta, lemos as imagens a partir de uma gramática que tenta desvelar quais são as mensagens ocultas que nossos antepassados nos enviaram pelos quadros, afrescos, estelas, etc. No entanto, não nos interessa vê-las, aqui, como textos cifrados em símbolos, prontos a serem lidas para desvelar o espírito que animou um tempo antanho. Antes de vê-las como janelas para outras paisagens ou símbolos da alma de outros tempos, podemos tomar as imagens como simples ações relacionais imagéticas de um contexto específico. Tais relações feitas imagens foram (e são) coadunadas com toda outra diversidade de restos de ações que destes outros tempos chegaram a nós e, por isso, servem para que pensemos as relações que as constituíram e as relações que estas constituíam (no seu momento e lugar específicos). Ou seja, as imagens são um conjunto de relações tornado corpo pela tinta, pela luz, por computadores, e, deste modo, servem como um nó onde podemos investigar a rede de relações onde se inseriam.

Não se trata de tachar a imagem de enganosa, mas sim de perceber que seria um engano tomar uma imagem enquanto evidência presente do que lá está representado para além dela, assim como seria

Educação \& Realidade, Porto Alegre, v. 39, n. 4, p. 1153-1168, out./dez. 2014.1155 Disponível em: <http://www.ufrgs.br/edu_realidade> 
A Imagem e as Ciências Humanas

também um erro simplesmente desconsiderá-la, nestes estudos de civilizações e culturas distantes pelo tempo e/ou espaço, por ser demasiado fugaz e mentirosa na sua relação com o real. Para além da verdade ou da mentira dos referentes (da designação e do significado) está o sentido que esta constitui ao afirmar-se no mundo, ao individuar-se imageticamente nos encontros de então.

Exemplo destes enganos pela ingênua redução da imagem à analogia verossimilhante (representação) ou falsidade precária (simulação), é a hipótese de Ariès de que as crianças se vestiam como pequenos adultos nos séculos XVII e XVIII, sem considerar as especificidades expressivas e o contexto em que ocorria a criação das imagens (Burke, 2004). Não há dúvida de que a imagem insere-se no cotidiano constituindo a sociedade, no entanto, insere-se agindo e não reproduzindo. Deste modo, por exemplo, o modo como as crianças estão vestidas em uma pintura é apenas "o modo como estas crianças estão vestidas para serem retratadas, por este artista, nesta pintura”, e pode estar falando mais sobre a pompa desta circunstância (ser retratado) em um período e localidade específicos, do que sobre as indumentárias comuns deste período e localidade: "Em outras palavras, como no caso de retratos de indivíduos, representações da sociedade nos dizem algo sobre uma relação, a relação entre o realizador da representação e as pessoas retratadas" (Burke, 2004, p. 149). As imagens, assim como os homens e os bules, são relações: Encontros diversos a dar corpo a corpos.

Do mesmo modo, o efeito do "realismo aparente" (Burke, 2004, p. 142) não é mero artifício com fins de propaganda religiosa ou política e, tampouco, se reduz a um respeito pelo motivo retratado. Antes se trata de uma estilística a qual não tem uma relação necessária com um referente perante o qual seja verossimilhante. O realismo na pintura, no audiovisual ou na fotografia, não é a evidência de referente, mas sim um modo de afirmar, uma estilística de expressar-se, a qual finda por gerar um efeito de convencimento da presença do referente, ainda que muitas vezes tal referente seja sabidamente inexistente. Portanto, para além do conflito entre idealização ou demonização da realidade da imagem, vemos a necessidade de atentar para a complexa trama que modula uma estilística e individua uma obra. Neste contexto, ao produzirmos imagens que pensam, não devemos ingenuamente buscar a representação do mundo (referente) ou das ideias (símbolo) tal qual são. Ao invés disso, podemos apenas transpassar o mundo com um olhar e dar corpo às imagens e sons que se produzem neste encontro: dar vazão às forças para além da experiência, com a experimentação. Ou seja, ao darmos luz a uma imagem, criamos também um mundo que a acompanha: nuances que ressaltam elementos, perspectiva que afirma modos de ver, cores que estabelecem padrões, linhas que delimitam conceitos, gestos que firmam relações. Assim como o mundo, a imagem também é uma ação.

1156 Educação \& Realidade, Porto Alegre, v. 39, n. 4, p. 1153-1168, out./dez. 2014 Disponível em: <http://www.ufrgs.br/edu_realidade> 


\title{
A Imagem para Além da Representação: as potências da poética experimental
}

Deste modo, podemos arguir que a imagem constrói ou não relações analógicas a partir de sua modulação em uma estilística nas relações que a constituem e que esta produz. Trata-se de cadeias divergentes de variação que perspectivam universos estilisticamente distintos. É esta a diferença entre tomar uma foto, vídeo, filme ou animação como evidência, elaborar e explorar suas relações miméticas, ver ao mundo representado utilizando-a apenas enquanto uma bizarra lente crua que não cria, mas somente captura ao visto em uma superfície; ou, de outro modo, tomar uma foto, vídeo, filme ou animação, nas suas relações, como expressão singular, matéria expressiva fluida a ser composta-decomposta, vista em sua ação relacional pictóriconceitual.

\begin{abstract}
Pensa-se então na fotografia (e demais meios) documental como aquela que acentua a importância do referente e do dispositivo óptico na formação da imagem e na fotografia experimental como aquele que tenderia a conferir prioridade à interferência da subjetividade do fotógrafo, inclusive de modo a que os efeitos visuais decorrentes do uso criativo dos equipamentos fotográficos estejam referidos a sua sensibilidade (Fatorelli, 2003, p. 31).
\end{abstract}

Trata-se, portanto, de uma questão de acento relacional, de sotaque imagético: a estilística é realista por si e não por uma relação de verossimilhança com um objeto real. É nesta modulação entre o experimental e o documental que veremos, portanto, a paradoxalização entre inteligível e sensível afirmar-se. Entre o documental e o artístico, o científico e o poético, vemos a operação de uma bruma paradoxal que torna um no outro que retorna outro no um ${ }^{1}$. Jean Rouch, por exemplo, desterritorializou a câmera-antropológica das suas bases estáveis: do tripé (provendo-a de mobilidade espacial) e da centralidade do olhar do antropólogo (compartilhando com seus objetos os processos de filmagem e edição). No entanto, tais experimentações não ressoaram de pronto no território da ciência: "Seu 'cine-transe' acabou tendo muito mais influência sobre cineastas como Truffaut e Godard do que sobre os antropólogos que realizavam filmes etnográficos" (Novaes, 2009, p. 48).

A partir do momento em que não se toma a imagem apenas por sua relação de documento, de evidência, ou seja, no momento em que ultrapassamos a relação simétrica imagem-referente que geralmente construímos com as imagens, assim a partir deste momento também poderemos ultrapassar a concepção de que as imagens são o artifício do demônio (ou do capital), e seremos capazes de utilizá-las para enriquecer nossa realidade, subvertê-la, recriá-la. Uma imagem sensível e inteligível: imagem como ensaio. A construção de uma poética imagética des(re)construindo as paisagens com as quais nos relacionamos, isto é a imagensaio (Dubois, 2004).

Educação \& Realidade, Porto Alegre, v. 39, n. 4, p. 1153-1168, out./dez. 2014.1157 Disponível em: <http://www.ufrgs.br/edu_realidade> 
A Imagem e as Ciências Humanas

O cinema e a fotografia desenvolveram-se em conjunto com nossa experiência das cidades modernas e contemporâneas, desenrolou assim, grande parte de suas experimentações sobre o próprio território urbano e seus fluxos cotidianos, ajudando a criar os sentidos dos mesmos e, por isso, alguns dos melhores exemplos, tanto da imagem como representação como da imagem poética, versam sobre o espaço das cidades: representando ou fazendo delirar o urbano. Podemos então andar pela cidade, guiados pelos fluxos persecutórios ordenados pela marca do crime, da guerra ou da catástrofe, segundo a câmera do telejornal ou do filme de guerra, ação, suspense, entre outros. Ou então, podemos buscar uma imagem-flaneur, em uma deriva urbana, apaixonando-se por pequenos elementos e gestos dos cotidianos das cidades, dando corpo a atmosferas poéticas e não a referentes claros e objetivos. Assim, sem um objetivo claramente delimitado nos permitimos fluir, flanando pelas linhas das paisagens, acariciando-as com movimentos do olhar e capturando seus ritmos com a câmera: "Oposto do repórter - e do fotógrafo de guerra - é aquele que vagueia, a câmera na mão, sem direção nem horário, pelas ruas. Ou aquele que, como um paisagista, contempla o panorama do mundo" (Peixoto, 1992, p. 429). Podemos nos deixar levar pela velocidade da cidade sem sermos necessariamente tomados pela pressa: seguir a vertigem ao modo de uma montanha russa ou viagem psicodélica, sem a gravidade da urgência dos passos que só existem pelo seu fim - casa, banco, hospital, shopping, carro, trabalho. Ter tempo para ver, para forçar ver transgredindo a visão, assim como o ato de pensar: dar outra visão ao "visível sempre visto" (visto demais, tão visto que não se pode nem ver e nem deixar de ver), olhar de viés para desamarrar o nó veloz e imóvel que garante o clichê: “[...] para evidenciar a força e a atmosfera que deles (rostos e paisagens) emanam" (Peixoto, 1992, p. 430). Acontecimentalizar (Foucault, 1990) nossa relação com a paisagem operando com o dispositivo produtor de imagens uma visibilização das pequenas percepções imperceptíveis: a atmosfera (Gil, 1996), o clima, ou o air (Barthes, 1989). Fazer ver a este sensível-inteligível que faz nos agenciarmos com a imagem para além de uma relação de representação descritiva e enumerativa das coisas do mundo. Ao invés de usarmos as imagens urbanas apenas para conhecer as cidades, podemos usá-las para aprender novos modos de ver nossa própria morada. As imagens das cidades jamais foram apenas descritivas: elas desviam nosso olhar para outras possibilidades de ver que eram por nós desconhecidas. Deste modo se elaborou uma infinidade de filmes que afirmam modos de ver delirantes sobre diversas cidades: $O$ Homem com a Câmera de Dziga Vertov (1929) sobre Moscou, Berlim: sinfonia de uma cidade de Walter Ruttmann (1927), São Paulo: sinfonia da metrópole de Rodolfo Lustig e Adalberto Kemeny, Roma de Fellini (1972), Duas ou três coisas que sei sobre ela, de Godard (1967). Nestes ensaios audiovisuais, o principal personagem é a cidade e seus cotidianos, de onde se desprende uma atmosfera poética singular a cada um dos núcleos

1158 Educação \& Realidade, Porto Alegre, v. 39, n. 4, p. 1153-1168, out./dez. 2014 Disponível em: <http://www.ufrgs.br/edu_realidade> 
urbanos. Há nestes filmes (e em outros, claro) um discurso antropológico, urbanístico e artístico que tornam arte e ciência híbridos através das longas sequências onde se faz poesia visual com a matéria prima da vida cotidiana: sem limitar-se a simplesmente descrevê-la, os autores dão corpo e luz a elementos não propriamente visuais do seu objeto, justapondo realidades distantes mas conectadas por outros meios que não o espaço-tempo, apresentando perspectivas insuspeitas da cidade por seus usuais transeuntes, alterando tempos e medidas dos passeios diários, enfim, utilizando-se de experimentações várias para obter efeitos intempestivos e poéticos, possibilitar um outro olhar sobre a cidade.

Tais experimentações poéticas não se apresentaram de imediato. Quando da criação das tecnologias de registro tal como a gravação em áudio e o cinema, seus inventores provavelmente mais atrelados à ciência que a arte, viram-nas antes de tudo como magníficas técnicas de capturar as coisas do mundo registrando-as melhor que qualquer memória e descrevendo-as melhor que qualquer palavra ou pintura. No entanto, ao fundir o documental cru, próprio à tecnologia dos irmãos Lumière, com a longa tradição de produzir delírios sensíveis, dos ilusionistas, o cinema se fez poesia. Com o agenciamento da nova ciência de sensibilizar filmes com a velha arte de produzir ilusões, o cinema tomou-se das operações que lhe permitem até hoje pensar ensaisticamente: trucagens, incrustações, sobreposições e toda uma diversidade de artifícios visuais que permitiram à imagem ir muito além do documental. Georges Meliè (1861-1938) foi quem experimentou a potência ilusionista do cinema e abriu-o à poesia: potência do falso de criar realidades outras. O olhar poderia agora ver o impossível, experimentar novas perspectivas que o arrancavam do senso comum e do bom senso, possibilitando imagens que pensam ao transgredir o já sabido, ver com outros olhos.

\begin{abstract}
Melhor que um automóvel, melhor que um avião, o cinematógrafo permite algumas trajetórias pessoais, e é toda a nossa física que estremece, é a mais profunda intimidade que se modifica. Mesmo habitando uma cidade, não a conhece quem não a visou na mira de um radiador, aproximada, penetrada, desdobrada no espaço e no tempo. [...] Não viu a terra quem não a viu sem abandonar seu movimento. É preciso girar mais depressa do que ela, e menos também (Epstein, 1974, p. 224-225 apud Dubois, 2004, p. 187).
\end{abstract}

Este fragmento de Jean Epstein (1897-1953), um dos principais experimentadores do início do cinema, fala de uma possibilidade de movimento que nos faz transpassar nossa perspectiva através da experimentação: em um primeiro momento podemos adentrar movimentos alheios, olhar por outros olhos, a partir de outros lugares (radiador do automóvel), acompanhar intimamente fluxos para perspectivar outra mirada (ver com o carro); já no outro momento podemos pelo fast ou slow motion, desviar do movimento no qual estamos tão integrados que

Educação \& Realidade, Porto Alegre, v. 39, n. 4, p. 1153-1168, out./dez. 2014.1159

Disponível em: <http://www.ufrgs.br/edu_realidade> 
A Imagem e as Ciências Humanas

mal o vemos, podemos então quebrar o ritmo, elaborar uma fuga em variações de modos de ver (acelerar e desacelerar para desgrudar de nossa perspectiva usual). Podemos, portanto, buscar no vídeo uma forma de outrarmo-nos, buscar um outro olhar além do nosso, um que nem existe. Inventar outras formas de ver, não para testar qual é o modo de compreensão verdadeiro, mas sim para produzir outras possibilidades de compreensão que enriqueçam nossa perspectiva sobre o mundo e seus modos. Sensibilizarmo-nos de sensibilidades outras: não para logo inteligibilizá-las pelo juízo como certas ou erradas, mas sim para nos imbuir de suas atmosferas afetivas, sua estilística, seu modo de ser.

Assim, no cinema, a experimentação intempestiva com a encenação, justaposição e sobreposição delirante também é a principal operação produtora de discursos imagéticos e, neste contexto, Dziga Vertov (1896-1954) foi um dos maiores pioneiros e entusiastas da experimentação audiovisual como possibilidade da liberação do olhar para além do humano em um pensar a cidade: uma câmera-olho que vê de modos (ângulos, velocidades, etc.) que o olho não poderia por si. Foi ele quem melhor realizou os planos de Eisenstein (1898-1948) que formalizara a possibilidade de uma linguagem própria do cinema não tributária à literatura e ao teatro em sua narrativa verbal, uma linguagem imagética baseada na constituição dos ideogramas orientais e sua operação de criar imagens com linguagem similares às figuras de linguagem verbais tão comuns à poesia e ao cotidiano. Com isso, elaborou os operadores visuais da metáfora e metonímia que, tais quais os processos primários do inconsciente freudiano (condensação e deslocamento), permitem a conjugação de imagens por sobreposição ou justaposição (como quadros sucessivos ou simultâneos), declinando-as em uma variedade de sentidos outros que os dados de imediato por cada uma isoladamente. Este cinema experimental, pleno de estratagemas poéticos que deixam claras as artificialidades do meio, foi atacado logo quando do seu surgimento pelos ímpetos naturalistas de um cinema realista (Machado, 2006).

\section{A Ontologia da Imagem e sua Poética: a concretude da imagem e sua ação}

Assim, percebemos que o sentido da imagem poética na produção do saber é a multiplicação de perspectivas possíveis e não a diminuição das imagens possíveis. Sem operar com o juízo e a necessidade de um terceiro excluído, uma gama diversa de perspectivas singulares podem coexistir possibilitando a experiência concreta (afetiva, intuitiva, pelo olhar) de uma alteridade rica e complexa. No entanto, a partir disso, como podemos compreender a realidade da imagem? Se nos colocamos para além de uma divisão entre falso e verdadeiro, imagem e referente, como podemos nós compreender a ontologia da imagem ela mesma? Como eu, que aqui estou escrevendo em um laptop, dentro do aparta-

1160 Educação \& Realidade, Porto Alegre, v. 39, n. 4, p. 1153-1168, out./dez. 2014 Disponível em: <http://www.ufrgs.br/edu_realidade> 
mento com a televisão ligada, a viver mil conexões imagéticas com o mundo todo, posso falar da realidade da imagem? O que é isso, então? Imagem? Como falar de fotos, pinturas, minha tela de computador e a tela da televisão em minha sala de estar? São partes concretas do mundo, isso é certo. Não são abstrações ou representações, são ações, ou melhor, são relações que possuem tendências de agenciamento conosco. Não são referentes de objetos outros, pois as imagens mesmas são realidades relacionais a complexificarem nossa trama-mundo. De que adiantaria separar imagem e mundo ao modo como fizemos com o corpo e a alma, o corpo e a mente, na história da filosofia ocidental? Temos que ultrapassar tais binarismos em uma perspectiva complexa e híbrida. Para tanto podemos nos valer da complexa ontologia elaborada pelo filósofo Alfred North Whitehead (1956), o qual nos apresenta um modo possível de univocidade entre imagem e mundo.

Com sua metodologia analítica (mas não reducionista) esse autor arranca da complexidade do mundo alguns conceitos puros que lhe servem de operadores da sua ontologia. Leva-nos então a uma série de conceitos os quais quando tomados isoladamente não nos são de grande serventia em decorrência de sua simplicidade, mas que quando considerados em relação, impuros e híbridos com os demais conceitos deste autor, nos levam a uma complexa relação com o mundo. Assim, se Whitehead nos fala, por exemplo, de um modo dos sentires ${ }^{2}$ (Whitehead, 1956) que é puramente físico e outro modo que é puramente conceitual, o que realmente nos importa aqui são as núpcias entre ambos no modo subjetivo: tais núpcias, para Whitehead, são o que gerarão o sentir que denominamos consciência. Sentir este que será a própria integração entre sentires físicos e espirituais (conceituais).

Dentro desta perspectiva das impurezas podemos averiguar que se torna sem sentido a investigação de nossas preensões ${ }^{3}$ em busca da sua pureza física e/ ou espiritual, posto que nós mesmos somos a produção da sua integração impura. Assim, Whitehead não nega a diversidade entre estas (possuem estilísticas singulares), mas torna a sua distinção em duas naturezas opostas um falso problema: resta-nos não elaborar a clássica bifurcação da natureza entre mente e corpo, dentro e fora, imagem e coisa, pensando assim que (como nos diz Whitehead citando Hume) a diferença entre o vermelho que toma nossa mente na escuridão e o vermelho que inunda nossos olhos em um dia ensolarado não são dois vermelhos de naturezas distintas (essência e aparência, substância e modo, real e mental, ilusório e verdadeiro etc.), mas sim vermelhos separados-unidos por uma diferença de nuances: "Esto significa que um sensualismo consecuente no puede distinguir entre un percepto y un concepto" (Whitehead, 1956, p. 330). Não há neste autor, portanto, um mundo dualista cindido entre alma e corpo, e, ainda que erija em seu lugar uma diferenciação modal entre os sentires físicos e conceituais, lhe importam intensamente as relações entre ambos em sentires híbridos e transmutados, onde sentires físicos tornam-se con-

Educação \& Realidade, Porto Alegre, v. 39, n. 4, p. 1153-1168, out./dez. 2014.1161 Disponível em: <http://www.ufrgs.br/edu_realidade> 
ceituais e sentires conceituais tornam-se físicos. Tal transmutação dos sentires entre si é a operação que produz Nexo, ou seja, a comunidade (coerência) de sentires: é assim que uma multiplicidade de sentires pode se unir em um só sentir complexo e heterogêneo fruto da apreensão desta multidão (jogando com suas intensidades, valorações e eliminações de modo a torná-los conjuntamente favoráveis e garantir sua metaestabilidade).

Vemos, portanto, a possibilidade de integrar as imagens ao universo das coisas corporais sem considerar as primeiras uma forma de degradação, ilusão, representação das segundas. Elas fazem parte desta unidade complexa, desta união metaestável e heterogênea que constitui nossos modos. Deste modo, a formação da imagem, para Whitehead, é um encontro de séries várias em composição (assim como todo sujeito, objeto, coisa, fluxo), como por exemplo, a série temporal do corpo humano (que nos leva ao olho e a visão tal como a conhecemos), do "objeto" fotografado/ pintado/ simulado, do dispositivo produtor da imagem etc. A imagem é, portanto, um “nexo”, uma preensão de preensões que relaciona estas séries entre si: "Los miembros de cada nexo serán contemporáneos entre si y la ruta historica conducirá al nexo que es la imágen" (Whitehead, 1956, p. 98).

Ao ver a série que constitui uma cadeira contemporânea a nós e a imagem que fazemos desta e, por fim, perguntar-nos "onde está a cadeira real?", Whitehead nos dá a hábil resposta de que a cadeira real é o conjunto de todas estas séries em questão, o nexo preensivo destes diversos nexos: "Esta sociedad es la silla real" (Whitehead, 1956, p. 98). Ou seja, nosso critério de validade onto-epistêmico repousa não em uma suposta essência ou substância para além das aparências de um ente, mas sim, na densidade da trama relacional que o constitui: A densidade ou coerência de sua ontologia repousa na multiplicação de perspectivas relacionais (modos de relação), mas sempre sem a possibilidade de alcançar um todo final (sempre há devir além, uma linha de fuga que leva a outra possibilidade, a outro ser, outra ontologia).

No entanto, ainda que tal perspectiva nos pareça por si suficiente, Whitehead, faz algumas ressalvas as quais findam por nos complicar a concepção da imagem e suas relações com a realidade e a ilusão. Para Whitehead (1956), a cadeira real, de fato, é a sociedade corpuscular (física) da série convergente cadeira e a sua história (variações de séries no tempo em composições variantes e formação de séries divergentes), excluindo as derivações desta em coisas como, por exemplo, reflexos no espelho. Estas seriam já outras histórias, novos nexos e o conceito de ilusão seria exatamente o ato onde inferimos um nexo onde está o outro. Deste modo, se a imagem da cadeira que olhamos está na cadeira mesma apreendemos (nos relacionamos com) a mesma série, no entanto, se miramos o reflexo da cadeira em um espelho, tratar-se-ia de outra série, outra composição sem relação de nexo com esta.

1162 Educação \& Realidade, Porto Alegre, v. 39, n. 4, p. 1153-1168, out./dez. 2014. Disponível em: <http://www.ufrgs.br/edu_realidade> 
Tal asserção nos apresenta dois elementos interessantes para a reflexão sobre a imagem: primeiramente, a ilusão não estaria no fato de não percebermos diretamente ao nexo, de vermos este apenas pela mente e não pela natureza ${ }^{4}$. O segundo elemento (o que não foi citado por Whitehead) é a imanência (concebida, aqui, como ausência de hierarquia ontológica, ausência de transcendentes) entre a imagem ilusória (espelho, pintura, foto etc.) e a usualmente denominada coisa em si (o físico, o corporal), posto que ambas nada mais são do que nexos, preensões, ocasiões atuais, ainda que distintas, sem qualquer déficit ontológico por qualquer das partes, ou seja, ambas são "ser", “objetos" (posto que todo objeto é um evento, uma relação).

Resta questionar por que, para este filósofo, não podemos atrelar as histórias de ambos os nexos (cadeira e reflexo da cadeira no espelho), complexificando ainda mais a ontologia do nó de relações denominado cadeira? Não formariam, cadeira e reflexo, também uma série em sua relação? Não constituiriam um novo nexo? Melhor seria para a filosofia e para as ciências sociais e humanas considerar (para além de organismos tão bem definidos por seus órgãos, em seus limites) que a cadeira real é uma miríade jamais extinguível de relações, ultrapassando em muito o chamado objeto cadeira, seu reflexo, ou mesmo as pessoas que nestas sentam, posto que podemos delimitar os limites relacionais que definem um ser, a partir de nossa pergunta, de nossa questão preensora, a qual possuirá seus próprios critérios de definição do ser em questão. Assim, por exemplo, a floresta, a mesa, o escritório, as pessoas e as costas, a ergonomia, a ascensão burguesa da ideia de conforto cotidiano, o trabalho imaterial contemporâneo, entre muitos outros elementos, podem fazer parte, de distintas formas, da constituição deste nexo-cadeira específico: "De esta suerte, un dato de los sentidos ingresa en la experiência en virtud de formar el qué de una integración multiple muy compleja de prehenciones en esa ocasión" (Whitehead, 1956, p. 99). Não podemos nos esquecer de que nesta imanência extensa de relações é também uma relação (preensão) que nos delimita como sujeitos e delimita nossos objetos ${ }^{5}$. Evidentemente não se trata de uma unificação identitária em um só ser, onde tudo pode tudo ser, o devir é delimitado pela sua própria série e suas potencialidades não são indeterminadas e sim condicionadas pelos seres e suas potências (ainda que o devir seja relativamente indeterminado ao abrir novas possibilidades nas ocasiões atuais, novas condições intempestivas).

Pensando assim ao mundo e às imagens, miro minha sala de estar e a vejo gorda de intensidades: perambulam à minha volta centenas de pequenas centelhas dos mais diversos lugares, ações transmitidas eletromagneticamente prontas a contaminar-me com suas singularidades prendendo-nos um ao outro. Há uma densidade de ações nas salas de estar contemporâneas, mundos que atualizam fragmentos de ações e se relacionam com nosso cotidiano. Tomam conta da atmosfera de nossas moradas com sua densidade de virtualidades sempre prontas a se apre-

Educação \& Realidade, Porto Alegre, v. 39, n. 4, p. 1153-1168, out./dez. 2014.1163

Disponível em: <http://www.ufrgs.br/edu_realidade> 
sentarem ali mesmo. A sala de estar tomada de presenças virtuais, de imagens do mundo, é uma sala densa que se espalha volta e meia para outros rincões. Trata-se de uma sala extremamente capilarizada, com microvilosidades imagéticas mil, as quais frequentemente escapam às paredes e vascularizam ao mundo e a sala de forma rica, complexa. Minha sala de estar vazia é uma multidão de mundos, pois, a partir de uma ontologia baseada na relação (preensão e sentires) e de uma concepção da imagem como relação (nexo, preensão), podemos considerar que estas (as imagens) possuem a mesma concretude em sua existência do que os demais corpos, podendo assim ser utilizadas para enriquecer nossas possibilidades de relação com o mundo.

\section{Os Sentidos das Imagens Poéticas na Produção de Saber}

Separando falazmente el fluir de la permanencia nos vemos llevados al concepto de un Dios enteramente estático, con realidad eminente, en relación con un mundo enteramente fluente, con realidad deficiente. Pero si los opuestos estático y fluente fueron explicados ya en el sentido de que caracterizan por separado actualidades diversas, la interacción entre la cosa que es estática y las cosas que son fluentes entraña contradicción a cada paso de su explicación (relação entre Deus transcendente e mundo imanente). Esas filosofías tienen que incluir la noción de ‘ilusión' como principio fundamental: la noción de 'mera apariencia'. Este es en última instancia el problema platónico (Whitehead, 1956, p. 465).

Podemos então efetuar a fuga das oposições constituídas pela filosofia ocidental, as quais relegaram as aparências ao status de pouco confiáveis e ardilosas, posto que o conhecimento é perene, eterno, do contrário não seria verdadeiro. Busque-se esta verdade em uma empiria restrita (descrição de corpos e movimentos) livre da subjetividade e poesia, há que se dar chumbo à imaginação dizia Bacon (1999), ou nas formas matemáticas puras tal qual um Descartes (1999), todos viam no iluminismo a imagem como um pária, uma ilusão que obscurece a razão, mera fantasia: “[...] o objeto é uma coisa, e a imagem ou ilusão outra" (Hobbes, 1999, p. 32). No entanto, ao unirmos a concepção ontológica elaborada por Whitehead (que finda com nossos preconceitos com a possibilidade de sermos enganados pelas imagens) com as já apresentadas possibilidades transformadoras da poética experimental (em suas transformações dos modos de ver em alteridades do olhar), percebemos que o sentido das imagens na produção de saber nas ciências sociais e humanas, aqui trabalhado, não se encontra no juízo, na verificação ou prova iluministas, mas sim na multiplicação de possibilidades de ver. Enquanto a ciência moderna buscou a simplificação dos fenômenos a um mínimo de fatores necessários para sua previsão e controle, a imagem poética produz um saber de caráter qualitativo onde buscamos multiplicar o número de variáveis ao máximo, lidando 
com informações fugazes e sutis, para tentar aproximarmo-nos não da generalização, mas sim da singularidade. Deste modo, com as diferentes perspectivas possibilitadas pela experimentação poética audiovisual, nós ampliamos nossa rede de relações (preensões) com o mundo, permitindo-nos modos de abarcar uma multiplicidade da qual não daríamos conta em outra situação.

A suspensão do juízo e decorrente abertura de sentidos, próprias da operação poética, podem ser formalizadas na figura elaborada por Charles Peirce de um raciocínio abdutivo. O juízo, para operar sua divisão entre o existente e o inexistente, entre o falso e o verdadeiro, se utiliza de produção de hipóteses que serão testadas (ajuizadas) em sua capacidade preditiva de um fenômeno qualquer: Se a hipótese prediz corretamente ao evento, é considerada válida, se é ineficaz, é considerada falsa. Do mesmo modo, se possuímos duas hipóteses para um mesmo evento, aquela que melhor controla e prevê aos eventos é considerada válida em detrimento da outra explicação. Caso ambas as hipóteses tenham a mesma capacidade de ação, opta-se em geral pela mais simples e elegante, segundo o princípio da navalha de Ockan (Gilson, 1998). O modo de pensar ao mundo proposto por Peirce com o nome de raciocínio abdutivo, não funcionaria segundo a mera elaboração de hipóteses falseáveis que irão competir entre si em um processo de incremento da eficácia e simplicidade até que reste apenas uma dentre elas. Ao invés de pressupor esta corrida da purificação científica, o raciocínio abdutivo propõe uma produção selvagem de hipóteses diversas e dispares, as quais não serão consideradas mutuamente excludentes, mas antes possibilidades contemporâneas. Pode-se, inclusive, operar deslocamentos de hipóteses provenientes de outros campos do saber, elaborando novas preensões entre disciplinas antes isoladas. A coexistência deste campo de possibilidades hipotético produz então, com as tensões existentes entre as diferentes hipóteses, uma série de transduções que possibilitam as relações entre as disparidades sem totalizá-las em uma nova unidade. Com esta máquina complexa e heterogênea de produções hipotéticas, podemos nos relacionar com os eventos do mundo sem simplificá-los, mas antes promovendo uma multiplicação das suas leituras possíveis, multiplicando nossas preensões possíveis com os eventos do mundo.

As imagens poéticas podem nos prover um dispositivo para a criação de tal máquina rizomático-hipotética, ampliando nossa potência de perspectivação da realidade. Já que estas imagens não nos propõem uma representação, uma relação rígida, simples e analógica entre a imagem e os eventos (objetos, ações, sujeitos, acontecimentos etc.), ela promove a criação de novas relações para além da mera designação e definição, permitindo o surgimento de novas preensões, nexos e perspectivas no mundo. Assim, tal afetação pela singularidade da imagem poética adentra nossa constituição ontológica mesmo, contribuindo com o desvio, com a fuga, com a emergência do novo. Pois, ao suspender

Educação \& Realidade, Porto Alegre, v. 39, n. 4, p. 1153-1168, out./dez. 2014.1165

Disponível em: <http://www.ufrgs.br/edu_realidade> 
o juízo e abrir os sentidos, ela nos provoca a ultrapassar o bom senso estabelecido, os significados prontos, promovendo um exercício de desassossego e crítica (Foucault, 1990) onde podemos reinventar ao mundo e a nós mesmos em outros.

A utilização e criação de imagens poéticas na produção de saber podem, portanto, servir para complexificar nossa trama discursiva e para intensificar a potência crítica deste discurso, levando necessariamente a uma relação de contágio e criação onde a narrativa poético-imagética provoca-nos que com ela se relacionam a disposição para criar novas possibilidades de olhares sobre o mesmo. Deste modo, a singularidade da atmosfera poética não se perde enquanto mera ilusão ou fato demasiado específico, pois permite a sofisticação de uma série de sentires e preensões outras para além desta relação específica a qual se estabeleceu. Olhar de poeta que aumenta a realidade com seus inventos relaciona elementos antes separados, cria novos territórios ainda inexplorados (Barros, 2010).

Recebido em 15 de julho de 2013 Aprovado em 02 de novembro de 2013

\section{Notas}

1 Por exemplo, tanto Étienne-Jules Marey quanto Eadweard Muybridge (ambos precursores do cinema, cada um ao seu modo, mas ambos com a fotografia em sua relação com o tempo) exploraram a decomposição-recomposição analítica do movimento humano e animal para seu estudo, mas ao mesmo tempo produziram interessantes efeitos plásticos com estas imagens e, para além disso, Marey, por exemplo, se aventurou mais a fundo na poética da imagem científica ao trabalhar com as pequenas percepções, os corpos luminosos e aéreos: nos trabalhos Mouvements de l'air e Corps Lumineux, por exemplo (Fatorelli, 2003).

2 "Sentires", são a unidade ontológica e epistêmica mínima na ontologia de Whitehead. O mundo para este filósofo é um mar de relações onde os sentires são suas gotas: condensações de experiências. E experiência, aqui, é tão concreta quanto o corpo, posto que ontologia e epistemologia são um só acontecimento. Os sentires acompanham a composição ou decomposição de nossas relações, e nossas relações são tijolos e cimento do mundo. Deste modo, temos uma ontologia modal, onde modos de experienciar são as oscilações do mundo mesmo em seus devires.

3 "Preensão" é não apenas um modo de composição do conhecimento, mas também o modo como se compõem os seres. Nesta relação, um ser afeta ao outro com sua própria singularidade, no encontro, sem contudo desfazer a singularidade própria a estes elementos envolvidos na dita preensão (sendo fundamental ressaltar que cada um dos elementos é também, ele mesmo, um complexo tornado coerente por uma preensão). Ou seja, simplificando ao conceito podemos considerar a "preensão" uma relação de composição ontológica e epistêmica entre termos diversos e singulares os quais também, por sua vez, são constituídos por preensões.

4 Ainda que tenhamos de nos perguntar se o ato de inferenciar um nexo-reflexo como sendo um nexo-cadeira não nos faria bifurcar a natureza novamente,

1166 Educação \& Realidade, Porto Alegre, v. 39, n. 4, p. 1153-1168, out./dez. 2014 Disponível em: <http://www.ufrgs.br/edu_realidade> 
sendo tal diferenciação entre percepção e inferência falha, posto que em toda percepção há um ou vários processos de inferência que possibilitam o perceber.

5 Nexo Ordem Social à Forma/ modo de relação comum entre diversos entes (ocasiões atuais) a qual surge a partir de algumas preensões entre estes mesmos seres. Em tal nexo, ou melhor, na preensão de tal nexo, há um sentir deste elemento/ modo comum, o qual se institui de modo virótico por influências múltiplas entre os entes deste nexo societário. A constituição desta conjunção virótica constitui uma lógica (ordem, leis) que passam a autorregular-se: são semelhantes por estarem em sociedade e estão em sociedade por serem semelhantes. Deste modo a constituição de uma identidade é na ontologia de Whitehead a construção de um nexo societário, e a constituição de uma série deste nexo é a criação de uma “orden personal" (Whitehead, 1956, p. 131).Nexo Ordem pessoal à É o nexo que se dá a partir de um nexo social, e nada mais é do que as séries de séries de variação das ocasiões atuais ordenadas em suas relações genéticas, suas relações de produção. Ordem pessoal fala da constituição e perseveração de um estilo singular de relação (ocasião-pessoa).

\section{Referências}

BACON, Francis. Novum Organum. São Paulo: Ed. Nova Cultural, 1999.

BARROS, Manoel de. Poesia Completa. São Paulo: Texto editores ltda, 2010.

BARTHES, Roland. A Câmera Clara: notas sobre fotografia. Rio de Janeiro: Nova Fronteira, 1989.

BURKE, Peter. Testemunha Ocular: história e imagem. Bauru: EDUSC, 2004.

DESCARTES, René. As Meditações. São Paulo: Ed. Nova Cultural, 1999.

DUBOIS, Philippe. Cinema, Vídeo, Godard. São Paulo: Cosac Naify, 2004.

FATORELLI, Antonio. Fotografia e Viagem: entre a natureza e o artifício. Rio de Janeiro: Relume Dumará, 2003.

FOUCAULT, Michel. O que e'a Crítica. Qu'est-ce que la critique? Critique et Aufklärung. Bulletin de la Société Française de Philosophie, v. 82, n. 2, p. 35-63, abr./jun. 1990. Tradução de Gabriela Lafetá Borges e revisão de Wanderson Flor do Nascimento. Disponível em: <http://www.unb.br/fe/tef/filoesco/foucault/ critique.html>. Acesso em: 15 jun. 2009.

GIL, José. A Imagem-Nua e as Pequenas Percepções: estética e metafenomenologia. Lisboa: Relógio D'Água Editores, 1996.

GILSON, Etienne. A Filosofia na Idade Média. São Paulo: Martins fontes, 1998.

HOBBES, Thomas. Leviatã. São Paulo: Ed. Nova Cultural, 1999.

NIETZSCHE, Friedrich. Obras Incompletas. In: Os Pensadores. São Paulo: Nova Cultural, 1999.

NOVAES, Sylvia Caiuby. O Uso da Imagem na Antropologia. In: SAMAIN, Etienne (Org.). O Fotográfico. São Paulo: Ed. Hucitec, 1998. P. 107-115.

NOVAES, Sylvia Caiuby. Imagem e Ciências Sociais: trajetória de uma relação difícil. In: BARBOSA, Andréa; CUNHA, Edgar da; HIKIJI, Rose (Org.). Imagem-Conhecimento: antropologia, cinema e outros diálogos. Campinas: Papirus, 2009. P. 35-60.

MACHADO, Arlindo. O Filme-ensaio. In: XXVI CONGRESSO BRASILEIRO DE CIÊNCIAS DA COMUNICAÇÃO. Intercom - Sociedade Brasileira de Estudos Interdisciplinares da Comunicação. Belo Horizonte, setembro de 2006.

Educação \& Realidade, Porto Alegre, v. 39, n. 4, p. 1153-1168, out./dez. 2014.1167

Disponível em: <http://www.ufrgs.br/edu_realidade> 
PEIXOTO, Nelson Brissac. Ver o Invisível: a ética das imagem. In: NOVAES, Adauto (Org.). Ética. São Paulo: Ed. Compania das letras, 1992. P. 301-320.

WHITEHEAD, Alfred North. Proceso y Realidad. Buenos Aires: Editorial Losada, 1956

Luis Artur Costa é psicólogo e artista plástico. Mestre em Psicologia Social UFRGS. Doutor Interdisciplinar no PPGIE/CINTED UFRGS. Pesquisador do Grupo Corpo, Arte e Clínica (UFRGS). Docente Adjunto do Curso de Psicologia da Universidade Federal de Pelotas, elabora pesquisas na área dos hibridismos metodológicos entre as Artes e as Ciências Sociais e da Educação. E-mail: larturcosta@gmail.com

Tania Mara Galli Fonseca é docente no PPGPSI e PPGIE UFRGS. Coordenadora do grupo de pesquisa Corpo, Arte e Clínica. Dirige a Coleção Cartografias, editada pelas editoras UFRGS e Sulina. Atualmente coordena o Projeto de pesquisa Arquivo e Testemunho de vidas infames: restos que insistem, que toma o Hospital Psiquiátrico São Pedro (HPSP) Porto Alegre/RS como campo empírico.

E-mail: tfonseca@via-rs.net

Margarete Axt é docente no PPGPSI e PPGIE UFRGS. Coordenadora do Laboratório de Estudos em Linguagem, Interação e Cognição, FACED/ UFRGS, buscando possibilidades de interlocução da educação com os estudos em filosofia da linguagem e filosofia da diferença, nas interfaces com a psicologia (social e cognitiva).

E-mail:maaxt03@gmail.com 